\title{
Identificação de micoplasmas pela inibição de crescimento de amostras isoladas de culturas celulares*
}

\author{
Identification of mycoplasma samples isolated from cell cultures by the growth \\ inhibition test
}

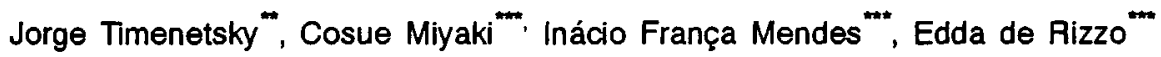

\begin{abstract}
TIMENETSKY, J. et al. Identificação de micoplasmas pela inibição de crescimento de amostras isoladas de culturas celulares. Rev. Saúde públ., S.Paulo, 26 (1): 17 - 20, 1992. As culturas celulares devem ser continuamente monitoradas quanto à presença de micoplasmas, pois, embora às vezes eles passem despercebidos, podem causar alterações cromossômicas, interferir na replicação viral, na produção de anticorpos e interferon. A Organização Internacional em Micoplasmologia (IOM) recomenda 0 isolamento e a identificação de micoplasmas, visando detectar as prováveis origens da infecção e melhorar a qualidade das culturas. Assim, foram analisadas pela inibição de crescimento, 37 amostras pertencentes a 27 linhagens celulares contaminadas por micoplasmas. Em nenhuma amostra foi observada a ocorrência de duas espécies. Foram idenfificados 18 (48,65\%) Mycoplasma arginini, 15 (40,55\%) Acholeplasma laidlawii, dois $(5,40 \%)$ Mycoplasma orale, sendo que duas amostras $(5,40 \%)$ não foram identificadas. Considerando as espécies caracterizadas na pesquisa, os autores sugerem: a) a adoção do teste de isolamento de micoplasmas em caráter de rotina; b) o aprimoramento das técnicas de assepsia e desinfeç̧ão; c) a eliminação da pipetagem bucal; d) a utilização de soros e de outros componentes de meios de cultura de qualidade certificada; e) o questionamento da presença de micoplasmas quando linhagens celulares são permutadas pelas instituições; f) a avaliação cautelosa de resultados obtidos quando se utilizam culturas infectadas por esse microrganismo.
\end{abstract}

Descritores: Células cultivadas, microbiologia. Micoplasma, isolamento. Técnica de tipagem bacteriana.

\section{Introdução}

Atualmente, culturas celulares não têm seu uso restrito à Virologia, sendo utilizadas em diversas áreas da pesquisa biomédica. Por constituírem sistema biológico sensível a agentes físicos, químicos e infecciosos, devem apresentar-se íntegras, de modo a não prejudicarem os ensaios laboratoriais. O monitoramento das culturas celulares deve ser permanente e incluir a pesquisa de micoplasmas porque estes microrganismos são capazes de provocar alterações citogenéticas ${ }^{6,7,8,10}$.

Com a produção, permuta e comercialização de culturas celulares, inicialmente isentas de micoplasmas, nem sempre é possível assegurar que eles

\footnotetext{
Pesquisa realizada com apoio financeiro do FEDIB (Fundo Especial de Despesas do Instituto Butantan)

Departamento de Microbiologia, Instituto de Ciências Biomédicas da Universidade de São Paulo

Seção de Cultura de Tecidos e Controle do Serviço de Virologia do Instituto Butantan

Separatas/Reprints: J. Timenetsky - Av. Prof. Lineu Prestes, 1374 - Ed. Biomédicas II - 05508 - São Paulo, SP - Brasil Publicação financiada pela FAPESP. Processo Saúde Coletiva 91/4994-0
}

continuem ausentes, pois, com a sucessão de repiques, a transposição do microrganismo para elas, às vezes, é inevitável. O soro animal, por exemplo, mesmo após passar através de membranas filtrantes com porosidade de $0,22 \mu \mathrm{m}$, pode conter micoplasmas, já que estes, sob determinadas condições fisiológicas, atravessam os poros ${ }^{8,10,15}$.

As taxas de infecção por micoplasma em culturas celulares variam de acordo com os fatores interferentes na manipulação, existentes em cada laboratório. Assim, $15 \%$ de infeç̧ão não constituem freqüência inesperada ${ }^{1,6,10}$.

No Brasil, Barth e Majerowicz (1988) ${ }^{3}$ detectaram micoplasma através da microscopia eletrônica, em soros e culturas celulares, enquanto que Miyaki e col. (1989) ${ }^{11}$, através de cultivo direto, verificaram a presença de Mycoplasma sp. em $45,28 \%$ de 106 culturas celulares examinadas. Timenetsky $(1990)^{15}$, através de provas diferenciais (bioquímicas), identificou Acholeplasma laidlawii em $88,23 \%$ de 17 linhagens celulares pesquisadas. Apesar desses dados ${ }^{3,17,15}$ não terem sido confirmados sorologicamente, as evidências parecem indicar que contaminações de culturas celulares, no Brasil, são freqüentes e dignas de avaliação. 
Dando continuidade às pesquisas nas quais os autores citados isolaram micoplasmas de culturas celulares $^{11,15}$, o presente trabalho visa a identificar sorologicamente, por inibição de crescimento, as cepas obtidas, utilizando antisoros especialmente produzidos, de modo a atender à recente recomendação da Organização Internacional em Micoplasmologia (IOM), de aprimorar o controle de micoplasmas em culturas celulares 5 .

\section{Material e Método}

Células pesquisadas - Provenientes de cinco laboratórios, 37 amostras de culturas celulares pertencentes a 27 linhagens comprovadamente contaminadas por micoplasma ${ }^{11,15}$, foram submetidas a uma ou mais passagens em caldo e em agar PPLO, e a testes que visaram à sua identificação. Em alguns casos, uma mesma linhagem foi recebida de mais de um laboratório, ou foi testada em passagens de cultivo diferentes. As culturas foram recebidas de seus respectivos laboratórios em garrafas, formando camadas confluentes, ou em suspensão, contidas em ampolas de congelação ${ }^{11}$. As linhagens pesquisadas e seus respectivos tecidos de origem foram os seguintes: $\mathrm{AV}_{3}$ (amnion humano); CPF-III (fibroblasto de embrião humano); HEL (pulmão de embrião humano); HeLa (carcinoma epidermóide de cervix humana); HEp2 (carcinoma epidermóide de laringe humana); KB (carcinoma epidermóide oral humano); PF (prepúcio humano); RH '(rim humano); BGM, BS-C-1, RITA (GMK modificada), VERO-76 (modificada) e VERO (rim de macaco verde - Cercopithecus aethiops); LLC$\mathrm{MK}_{2}$ e MA-104 (rim de macaco Rhesus - Macaca mulatta); GBK (rim bovino); $\mathrm{SK}_{6}$ (rim suíno); A72 (tumor de cão de histologia desconhecida); CRL-1430 (timo de cão); CCL-94 e CRFK3 (rim de gato); RC (rim de coelho); SIRC (córnea de coelho); BHK-21 (rim de hamster); L-929 e NCTC (fibroblasto de camundongo); FLK (rim de cordeiro).

Teste de isolamento de micoplasma - Os testes de isolamento de micoplasma foram realizados pelo método de cultivo direto, em anaerobio$\mathrm{se}^{2,11,12,15}$.

Cepas de micoplasma padrāo - Na aferiçāo dos meios de cultivo e dos meios diferenciais foram utilizadas as seguintes cepas de micoplasma padrão: Mycoplasma gallisepticum USA-38502/ $56^{11}$; Acholeplasma laidlawii NCTC 10116; Mycoplasma orale NCTC 10112; Mycoplasma arginini ATCC $28383^{10}$.

Produção de soros hiperimunes - Coelhos adultos foram inoculados simultâneamente por via intradérmica e intramuscular (IM) com suspensão de cada cepa padrão de micoplasma (A. laidlawii,
$M$. orale e $M$. arginini), acrescida de adjuvante de Freund completo. Um reforço por via $\mathbf{I M}$ foi feito no $21^{9} \mathrm{dia}^{13}$. A sangria ocorreu três semanas após o reforço. Soro anti-Mycoplasma hyorhinis BS-7 ${ }^{\mathrm{T}}$ foi obtido no NIH (National Institutes of Health, USA).

Técnica de inibiçāo de crescimento - A técnica de inibição de crescimento obedeceu à descrição de Clyde.

\section{Resultados e Discussão}

Embora dados da literatura demonstrem que diversas espécies de micoplasma já foram encontradas em culturas celulares, $A$. laidlawii, $M$. arginini, $M$. orale e $M$. hyorhinis têm sido as mais freqüentes ${ }^{6,8,10}$.

As amostras de A. laidlawii que haviam sido anteriormente caracterizadas bioquimicamente ${ }^{15}$, na presente pesquisa foram confirmadas por sorologia, assim como as amostras de $M$. orale e de M. arginini.

Conforme consta na Tabela, das 37 amostras analisadas, 18 pertenciam à espécie $M$. arginini e 15 à $A$. laidlawii, enquanto que apenas duas amostras foram positivas para $M$. orale, ocorrendo também dois casos em que não foi possivel a identificação. Não foi observada a ocorrência de duas espécies de micoplasma numa mesma amostra.

As espécies de micoplasma identificadas que aparecem na Tabela são as mesmas citadas mais frequientemente na literatura. Entretanto, diferem em suas percentagens de ocorrência porque é possivel que outros fatores tenham interferido quando as culturas foram submetidas a procedimentos de manutenção, em seus laboratórios de origem ${ }^{6,8}$.

O M. orale é componente da microbiota da cavidade bucal humana e, quando encontrado em culturas celulares, parece resultar de técnicas de assepsia deficientes, principalmente a pipetagem bucal $^{6}$. As 15 amostras nas quais foi identificado A. laidlawii provinham originalmente de várias instituições que as repassaram a uma segunda, na qual foram feitos os repiques de manutenção das culturas. Como os meios de cultivo, soro fetal, tripsina e outros, utilizados na manutenção eram isentos de micoplasma, o fato pareceu sugerir que, anteriormente, ocorrera uma disseminação de micoplasma provocada por uma mesma via, contaminando as culturas ${ }^{15}$. No que se refere ao $M$. arginini, as 18 amostras foram provenientes de instituiçōes distintas, e a hipótese de uma disseminação de micoplasma a partir de uma só fonte não é aceitável, como aconteceu no caso anterior. Na literatura, $M$. arginini e $A$. laidlawii são citados como os contaminantes mais freqüentes de culturas de células porque na sua manutenção são usa- 
Tabela 1. Micoplasmas isolados de culturas celulares

\begin{tabular}{|c|c|c|c|c|c|c|}
\hline \multicolumn{2}{|c|}{ Linhagem Celular } & \multirow{3}{*}{$\begin{array}{c}\mathrm{N}^{2} \text { de } \\
\text { amostras } \\
\text { testadas }\end{array}$} & \multicolumn{4}{|c|}{ Espécies } \\
\hline \multirow[t]{2}{*}{ Origem } & \multirow[t]{2}{*}{ Nome } & & \multicolumn{3}{|c|}{ Identificadas } & \multirow{2}{*}{$\begin{array}{c}\text { Não } \\
\text { Identificadas }\end{array}$} \\
\hline & & & M. arginini & A. laidlawii & M. orale & \\
\hline $\mathrm{H}$ & $\mathrm{AV}_{3}$ & 1 & 1 & $\cdot$ & $\cdot$ & $\cdot$ \\
\hline$U$ & CPF-III & 1 & - & 1 & - & - \\
\hline$M$ & HEL & 1 & - & 1 & - & - \\
\hline $\mathrm{A}$ & HeLa & 1 & 1 & - & - & - \\
\hline$N$ & HEp2 & 4 & $3^{\circ}$ & 1 & - & - \\
\hline \multirow{4}{*}{ A } & $\mathrm{KB}$ & 1 & 1 & - & . & $\cdot$ \\
\hline & PF & 1 & - & 1 & - & - \\
\hline & $\mathrm{RH}$ & 1 & - & - & 1 & $\cdot$ \\
\hline & A.72 & 1 & 1 & - & - & - \\
\hline 0 & $B G M$ & 1 & 1 & - & - & - \\
\hline$u$ & BHK-21 & 3 & $2^{*}$ & 1 & - & - \\
\hline$T$ & BS-C.1 & 1 & 1 & . & . & - \\
\hline$R$ & CCL.94 & 1 & 1 & - & - & - \\
\hline$A$ & CRL-1430 & 1 & - & - & 1 & - \\
\hline \multirow[t]{2}{*}{$\mathrm{s}$} & $\mathrm{CRFK}_{3}$ & 1 & - & 1 & - & - \\
\hline & FLK & 1 & 1 & - & - & $\cdots$ \\
\hline$E$ & GBK & 1 & - & 1 & - & - \\
\hline $\bar{s}$ & LLC-MK & 3 & $2^{*}$ & 1 & - & - \\
\hline$P$ & L.929 & 1 & 1 & - & - & - \\
\hline$\dot{E}$ & MA-104 & 1 & - & 1 & - & - \\
\hline $\mathrm{c}$ & NCTC & 1 & - & 1 & - & - \\
\hline 1 & RC & 1 & - & 1 & - & - \\
\hline E & RITA & 1 & - & 1 & - & - \\
\hline \multirow[t]{4}{*}{$s$} & SIRC & 1 & 1 & - & - & - \\
\hline & $S K_{6}$ & 1 & - & 1 & - & - \\
\hline & VERO & 4 & 1 & 1 & - & $2 * \mathbf{A}$ \\
\hline & VERO-76 & 1 & - & 1 & - & $\cdot$ \\
\hline Total & 27 & 37 & $18(48,65 \%)$ & $15(40,55 \%)$ & $2(5,40 \%)$ & $2(5,40 \%)$ \\
\hline
\end{tabular}

Catabolismo da glicose positivo, ausência de produçáo de filme, hidrólise de arginina negativa e rẹduçāo de tetrazólio negativa.

"Micoplasmas identificados em amostras distintas, pois não foi observada a ocorrência de duas espécies numa mesma amostra.

dos soros obtidos de bovinos, que são hospedeiros naturais dessas espécies.

Apesar do M. hyorhinis, que parasita suínos, não ter sido identificado nesta pesquisa, sua presença em culturas celulares justificar-se-ia pelo uso de soro bovino proveniente de matadouros mistos. A tripsina, produto suíno, na prática não transporia micoplasma para as culturas celulares porque, da maneira como é utilizada, possui propriedades micoplasmacidas 9,10 .

Provas tais como a microscopia eletrônica, a evidenciação de colônias em forma de 'ovo frito', a sensibilidade à digitonina, a coração de Dienes, a diferenciação bioquímica, embora sejam muito eficientes na caracterização de micoplasmas, são insuficientes para sua identificação sendo, portanto, necessária uma avaliação sorológica baseada na inibição de crescimento.
As espécies de micoplasma encontradas no presente estudo causam diversas alterações citogenéticas, interferem na obtenção de partículas virais, anticorpos, interferon e outros. Entretanto, apesar de sua infecção em determinadas linhagens celulares não causar efeitos visíveis, passando aparentemente despercebida, os resultados de testes realizados com células que contêm micoplasmas devem ser avaliados com cautela ${ }^{8}$.

Convém lembrar que a permuta de linhagens celulares entre instituições possibilita, em nosso meio, a aquisição de culturas contaminadas, pois o controle de micoplasma nem sempre é realizado, embora dependa de teste relativamente simples, que deveria ser implantado como rotina em todos os laboratórios.

A Organização Internacional em Micoplasmologia (IOM) recomenda o isolamento e a identifi- 
cação de micoplasmas presentes em culturas celulares visando a detectar as fontes de contaminação e melhorar a sua qualidade. A caracterização de uma espécie permite aprimorar técnicas de assepsia e desinfecção, questionar a pipetagem bucal, incentivar a utilização de soros de origem animal, de meios de cultura e de tripsina isentos de micoplasma, e prevenir a formação de aerossóis evitando assim a sua disseminação para outras culturas ainda isentas $5,6,8,10,14$.

TIMENETSKI, J. et al. [Identification of mycoplasma samples isolated from cell cultures by the growth inhibition test.] Rev. Saúde públ., S.Paulo, 26 (1): 17 - 20, 1992. Cell cultures must be continuously screened for the presence of mycoplasma because, although these microorganisms sometimes pass unoticed, they may cause chromosomic alterations and interfere with viral replication, antibody and interferon production etc. The International Organization for Mycoplasmology (IOM) recommends the isolation and identification of mycoplasma with a view to the detection of the origin of the infection and the improvement of the quality of the cultures. In this paper, 37 samples belonging to 27 cell lines contaminated with mycoplasma were assayed by the growth inhibition test. It is known that Mycoplasma orale is the most common human mycoplasma contaminant of cell cultures, the major vehicle of contamination being mouth pippeting, while commercial bovine serum in the main source for Mycoplasma arginini and Acholeplasma laidlawii. M. arginini was found in $18(48.65 \%)$ of the cell samples tested, A. laidlawii in 15 $(40.55 \%)$, and $M$. orale in two $(5.40 \%)$. Two other samples could not be identified by the antisera used (antisera against $M$. arginini, $M$. orale, Mycoplasma hyorhinis and A. laidlawii) their characteristics being "fried egg" colonies, digitonine sensitivity, Dienes stained, positive glucose catabolism, negative arginini hydrolysis, and negative tetrazolium reduction. No more than one type of mycoplasma was found in each cell culture. In the light of the results of the study, it is suggested that: a) cell cultures should be tested for mycoplasma on a routine basis; b) microbial control techniques be improved; c) mouth pippeting be abolished; d) serum and cell culture media components purchased be of certified quality; e) the presence of mycoplasma when cell lines are exchanged among institutions be investigated; $f$ ) data obtained when mycoplasma infected cell cultures are used be carefully evaluated.

Keywords: Cells, cultured, microbiology. Mycoplasma, isolation. Bacterial typing technics.

\section{Referências Bibliográficas}

1. BARILE, M.F. Mycoplasma contamination of cell cultures: incidence, source, prevention and problems of elimination. In: Kruse Jr., P.F. \& Peterson Jr., N.K., eds. Tissue culture methods and applications. New York, Academic Press, 1973. p. 729-35.

2. BARILE, M.F. \& McGARRITY, G.J. Isolation of mycoplasmas from cell cultures by agar and broth techniques. In: Razin, S. \& Tully, J.G., eds. Methods in mycoplasmology. New York, Academic Press, 1983. v. 2, p. 159-66.

3. BARTH, O.M. \& MAJEROWICZ, S. Rapid detection by transmission electron microscopy of mycoplasma contamination in sera and cell cultures. Mem. Inst. Oswaldo Cruz, Rio de Janeiro, 83: 63-6, 1988.

4. CLYDE Jr., W.A. Growth inhibition tests. In: Razin, S. \& Tully, J.G., eds. Methods in mycoplasmology. New York, Academic Press, 1983. v. 1, p. 405-10.

5. INTERNATIONAL ORGANIZATION FOR MYCOPLASMOLOGY (IOM). International Program on Comparative Mycoplasmology (IRPCM). Report of consultations. Baden, Austria, 1988.

6. McGARRITY, G.J. Detection of mycoplasmal infection in cell cultures. In: Maramorosch, K., ed. Advance in cell culture. New York, Academic Press, 1982. p. $99-131$.

7. McGARRITY, G.J. Precautions in handling infectious material. In: Razin, S. \& Tully, J.G., eds. Methods in mycoplasmology. New York, Academic Press, 1983. v. 1, p. 115-19.

8. McGARRITY, G.J. \& KOTANI, H. Cell culture mycoplasmas. In: Razin, S. \& Tully, J.G. eds The mycoplasma. New York, Academic Press, 1985. v. 4, p. 353-86.

9. McGARRITY, G.J.; SARAMA, J.; VANAMAN, V. Factors influencing microbiological assay of cell culture mycoplasmas. In Vitro, 13(2): 73-81, 1979.

10. McGARRITY, G.J.; SARAMA, J.; VANAMAN, V. Cell culture techniques. A.S.M. News, 51(4): 170-83, 1985.

11. MIYAKI, C.; PRAL, M.M.; GALLINA, N.M.F.; RIZZO, E. de. Micoplasma como contaminante de culturas celulares mantidas em laboratónios de instituições particulares e oficiais. Rev. Saúde públ., S. Paulo, 23: 39-44, 1989.

12. RAZIN, S. \& TULLY, J.G. Methods in mycoplasmology: mycoplasma characterization. New York, Academic Press, 1983. v. 1

13. SENTERFIT, B.L. Preparation of antigens and antisera. In: Razin, S. \& Tully, J.G., eds. Methods in mycoplasmology. New York, Academic Press, 1983. v. 1, p. 401-4.

14. STAMBRIDGE, E. Mycoplasma and cell cultures. Bacteriol. Rev.; 33: 206-27, 1971.

15.TIMENETSKY, J. Isolamento de Acholeplasma em diferentes culturas celulares. Rev. Microbiol., 21(2): 153-6, 1990. 